\title{
Etiologies of Maternal Mortality in the Hospital Provincial Janson Sendwe in Lubumbashi (DR. Congo)
}

\author{
Kanyeba Mulumba Odette ${ }^{1 *}$, Kanyiki Katala Moise1, Banza Ndala Deca Blood1, \\ Ciamala Paul Mukendi², Jean Mukendi Mukendi Réne², Ntumba Mukendi Kennedy², \\ Kabulo Kasongo Benjamin ${ }^{3}$, Kabumba Kabumba François ${ }^{4}$, Kabamba Nzaji Michel ${ }^{5}$, \\ Kalenga Mwenze Prosper 6
}

\begin{abstract}
${ }^{1}$ Department of Epidemiology, Community Health Section, Higher Institute of Medical Techniques of Mbuji-Mayi, Mbuji-Mayi, Democratic Republic of Congo

${ }^{2}$ Department of Teaching and Administration in Nursing, Nursing Section, Higher Institute of Medical Techniques of Mbuji-Mayi, Mbuji-Mayi, Democratic Republic of Congo

${ }^{3}$ Department of Pediatrics, Faculty of Medicine, University Official Mbujimayi, Mbuji-Mayi, Democratic Republic of Congo ${ }^{4}$ Department of Surgery, Faculty of Medicine, University Official Mbujimayi, Mbuji-Mayi, Democratic Republic of Congo ${ }^{5}$ Department of Public Health, Faculty of Medicine, University of Kamina, Kamina, Democratic Republic of Congo ${ }^{6}$ Department of Obstetrics and Gynecology, Faculty of Medicine, University Lubumbashi, Lubumbashi, Democratic Republic of Congo

Email: *drodettekanyeba@gmail.com
\end{abstract}

\footnotetext{
How to cite this paper: Odette, K.M., Moise, K.K., Blood, B.N.D., Mukendi, C.P., Réne, J.M.M., Kennedy, N.M., Benjamin, K.K., François, K.K., Michel, K.N. and Prosper, K.M. (2017) Etiologies of Maternal Mortality in the Hospital Provincial Janson Sendwe in Lubumbashi (DR. Congo). Open Access Library Journal, 4: e3502. https://doi.org/10.4236/oalib.1103502
}

Received: March 7, 2017

Accepted: March 27, 2017

Published: March 31, 2017

Copyright $\odot 2017$ by authors and Open Access Library Inc.

This work is licensed under the Creative Commons Attribution International License (CC BY 4.0).

http://creativecommons.org/licenses/by/4.0/ (c) (i) Open Access

\begin{abstract}
Objectives: The objective of this work was to analyze the etiologies of maternal deaths occurring in a tertiary hospital. Methodology: This is a descriptive cross-sectional study with retrospective data collection of maternal deaths that occurred in the reference provincial hospital Jason Sendwe from 2013 to 2015. All cases of maternal deaths in line with the definition of World Health Organization have been included. Data were analyzed by the software Epi info and Excel 2010 7.1.4.0. Results: Seventy seven (77) maternal deaths were identified during the study period. $74.03 \%$ of deaths occurred direct obstetric causes. Bleeding with $61.04 \%$ was the leading cause of maternal death followed by eclampsia (31.58\%). Indirect causes were dominated by heart disease (30.0\%). Note that $75.32 \%$ of deaths had occurred within 24 hours of admission. Conclusion: haemorrhage, eclampsia and infections are the main causes of maternal deaths in our study. The reduction of maternal deaths happens through access to emergency medication, transfusion and anesthetic and surgical teams in hospitals but also through the involvement of religious leaders, traditional and any community to better understand the population obstacles to reducing maternal mortality.
\end{abstract}




\section{Subject Areas}

Gynecology \& Obstetrics, Public Health

\section{Keywords}

Etiology, Maternal Mortality, Lubumbashi

\section{Introduction}

During the high-level meeting in September 2010 on the Millennium Development Goals, world leaders had expressed concern at the slow progress in improving maternal and reproductive health and reduce maternal mortality. The maternal mortality rate, which is the most common measure of maternal health remained a major challenge for Africa, especially in comparison with the rest of the world [1].

Maternal mortality is defined according to the World Health Organization (WHO) as the death of a woman while pregnant or of within 42 days after delivery, regardless of length or location, from any cause related to or aggravated by the pregnancy or its management but not from accidental or incidental causes [2].

According to WHO, more than $85 \%$ of maternal deaths occur in sub-Saharan Africa and South Asia. In European countries and the United States, although maternal mortality is low, a number of studies have highlighted disparities by ethnicity of the mother [3] [4] [5] [6]. In other words, the maternal mortality rate is variable depending on the socio-economic level of a country. Indeed, it is lower in developed countries than in developing ones.

Maternal mortality is the health indicator showing the greatest disparity between developing countries and developed countries. Maternal death should probably be avoided if good quality care and quick were insured [7].

In developing regions, the maternal mortality ratio is 450 maternal deaths per 100,000 live births, against 9 in developed regions. In total, 14 countries have a rate exceeding 1000 and, with the exception of Afghanistan, all of them are in sub-Saharan Africa: Angola, Burundi, Cameroon, Guinea-Bissau, Liberia, Malawi, Niger, Nigeria, Democratic Republic of Congo, Rwanda, Sierra Leone, Somalia and Chad. Apart from the differences between states, there are also wide variations in the countries themselves, between rich and poor and between urban and rural populations [8].

The Democratic Republic of Congo, our country had the $36^{\text {th }}$ highest rate of overall mortality in the world: 11.06 deaths/1000 people in 2011. With regard to maternal mortality, she had the MMR $16^{\text {th }}$ most high, with 670 deaths $/ 100,000$ births in 2008 [9].

Worldwide, about $80 \%$ of maternal deaths are due to direct causes while $20 \%$ are related to indirect causes. In order of importance, the four major direct causes of maternal death in Africa are: Haemorrhage, infection, hypertensive 
disorders during pregnancy and clandestine abortions. Among the indirect causes of maternal deaths (20\%), HIV/AIDS, anemia, malaria, cardiovascular diseases are the most common [10].

We proposed to analyze the etiology of maternal mortality in the Provincial Janson Sendwe Hospital, hospital structure tertiary service.

\section{Material and Method}

This cross-sectional descriptive study was conducted in the city of Lubumbashi precisely in the gynecology and obstetrics department of the reference hospital Provincial Jason Sendwe, the largest hospital structure du Haut Katanga and the only third level. The study population consisted of any woman who died during pregnancy or within 42 days of delivery. All maternal deaths recorded and identified by the gynecology and obstetrics department of the provincial hospital reference Jason Sendwe from 2013 until 2015 and meeting the definition of the World Health Organization has been included in this study and woman brought dead was excluded. The literature review of the different registers by using a pre-established questionnaire was conducted to collect data and related socio-demographic variables, the concept of antenatal monitoring, gestational age, circumstances and time of occurrence of death.

Prior authorization had been obtained from the Lubumbashi University Medical Ethics and the management of the Hospital Committee. The data were coded and analyzed using the software Excel 2010 and Epi-Info 7.1.4.0.

Being a retrospective study, this study did not take into account all the factors that may be at the basis of the occurrence of maternal mortality because not being able to be listed in the archives but also it cannot determine the risk factors of this mortality in our study environment.

\section{Results}

It emerges from Table 1 that the age group 20 to 34 was the most represented with 53.25\%. The average age of women was 29.5 Married women accounted for $76.62 \%$ and came from all towns of the city of Lubumbashi in the head the Common Kenya (22.08\%).

Table 2 shows that $38.96 \%$ of women had followed the ANC, in most cases, pregnancy had expired $(44.16 \%)$ and gestational age could not be determined in $28.57 \%$ of cases.

Table 3 shows that $74.03 \%$ of deaths occurred direct obstetric causes, including haemorrhage with $61.40 \%$. Indirect causes represented $25.97 \%$ with leading heart disease (30.00\%).

It appears from Table 4 that $75.32 \%$ of deaths were occurring before 24 hours and $18.18 \%$ after 48 hours.

\section{Discussion}

More than half of our sample consisted of women aged 20 to 34 years. These results agree with those of Tebeu et al who found that in 2007 women aged 25 to 
Table 1. Distribution of cases by age, marital status and origin.

\begin{tabular}{ccc}
\hline Characteristic of the woman & Effective & Percentage \\
\hline age range & 41 & \\
20 to 34 & 7 & $53.25 \%$ \\
Under 20 & 29 & $9.09 \%$ \\
35 and over & & $37.66 \%$ \\
Civil status & 59 & \\
Married & 18 & $76.62 \%$ \\
unmarried & & $23.38 \%$ \\
Origin & 12 & $15.58 \%$ \\
Annex & 7 & $9.09 \%$ \\
Kamalondo & 13 & $16.88 \%$ \\
Kampemba & 2 & $2.60 \%$ \\
Katuba & 17 & $22.08 \%$ \\
Kenya & 15 & $19.48 \%$ \\
Lubumbashi & 11 & $14.29 \%$ \\
Rwashi & & \\
\hline & & \\
\hline
\end{tabular}

Table 2. Distribution by monitoring EIC and age of pregnancy.

\begin{tabular}{ccc}
\hline Monitoring of pregnancy & workforce & Percentage \\
\hline CPN followed & thirty & $38.96 \%$ \\
Unknown & 17 & $22.08 \%$ \\
No & thirty & $38.96 \%$ \\
Yes & & \\
Age Pregnancy & 20 & $25.97 \%$ \\
prematurely & 22 & $28.57 \%$ \\
Unknown & 34 & $44.16 \%$ \\
Term & 1 & $1.30 \%$ \\
term exceeds & &
\end{tabular}

Table 3. Distribution of cases by causes of death.

\begin{tabular}{ccc}
\hline Type of case & Effective $(\mathbf{n}=\mathbf{7 7})$ & Percentage \\
\hline direct Causses & 57 & $74.03 \%$ \\
indirect Causses & 20 & $25.97 \%$ \\
direct causes & & \\
Eclampsia & 18 & $31.58 \%$ \\
Hemorrhage & 35 & $61.40 \%$ \\
Infection & 4 & $7.02 \%$ \\
\hline
\end{tabular}




\section{Continued}

\begin{tabular}{ccc}
\hline indirect Causses & & \\
Anemia & 3 & $15.00 \%$ \\
Other & 1 & $5.00 \%$ \\
heart disease & 6 & $30.00 \%$ \\
Diabetes & 1 & $5.00 \%$ \\
Renal failure & 2 & $10.00 \%$ \\
OAP & 4 & $20.00 \%$ \\
Malaria & 1 & $5.00 \%$ \\
Tuberculosis & 1 & $5.00 \%$ \\
HIV & 1 & $5.00 \%$ \\
\hline
\end{tabular}

Table 4. Distribution by duration of hospitalization before death.

\begin{tabular}{ccc}
\hline duration & Effective $(\mathbf{n}=\mathbf{7 7})$ & Percentage \\
\hline 24 to 48 hours & 5 & $6.49 \%$ \\
Beyond 48 hours & 14 & $18.18 \%$ \\
before $24 \mathrm{~h}$ & 58 & $75.32 \%$ \\
\hline
\end{tabular}

34 were more likely to die of causes related to pregnancy in Maroua in northern Cameroon [11]. Investigations of Kilolo Kamina indicated that the highest rates corresponded rather to women aged 19 to 35 (68.6\%) unlike many results reported in the literature and by which the extreme youth and old age pregnant women posed a risk of maternal death [12]. This could be explained by the fact that this period of life is when the woman is on top of the reproductive function and fertility peak of Congolese women in reproductive activity is usually between 25 and 29 confirm this explanation.

Direct obstetric causes, as described elsewhere in other studies [13] [14] [15] [16], were in the majority. Bleeding with $61.4 \%$ were the predominant cause; it remains a common and major cause in African countries [13] [14]. Our figures are consistent with those of other authors namely Horo et al. [17] in Ivory Coast in 2004, Gandzien et al. [18] and Traore et al. [19] in Mali in 2008 in Congo in 2002 who reported direct obstetric causes of maternal mortality with a domination of Bleeding 40\%, 44\%, 38.4\%. Hemorrhagic complications are sudden and unforeseeable and require a well-organized support; this involves material resources immediately accessible, competent and dynamic personnel; any delay or improvisation could contribute to a worsening of maternal prognosis. The haemorrhage is known for its rapid evolution towards a worsening (e.g. coagulopathy) and considerable blood loss requiring blood products.

Hypertensive diseases were the second leading cause of maternal deaths (31.58\%) in our study when they were in first or last position in other studies in Africa [16]. Our rate is considerably higher than that of our studies in developing countries [20]. A study by WHO/UNFPA/UNICEF/World Bank [21] found 
that hypertensive disorders of pregnancy especially eclampsia, are the source of approximately $12 \%$ of maternal deaths. The management of severe hypertension requires organization of care and skill of the emergency team, specifically, a methodical treatment in the referral maternity.

On the other hand Foumane $\mathrm{P}$ et al noted aprevalence of hypertension in pregnancy in their series, which is supported by several African works including a multicenter study conducted in Benin, Ivory Coast and Senegal where $29 \%$ of maternal deaths are due to hypertension. Similarly, preeclampsia is recognized to be the leading cause of maternal mortality in Latin America and the Caribbean [22].

The causes of death in our study are diverse, but in the majority of preventable cases almost $100 \%$. This result is comparable to those of Traore et al. [19] in 2008 in Mali, which is 95\% and Horo et al. [17] in 2004 in Ivory Coast that displays $98 \%$. It is higher than Nayama et al. [23] in Niger in 2001, which is $84.6 \%$.

In our study, $75.32 \%$ of deaths were occurring before 24 hours. Our numbers are similar to other studies in other African countries: Nayama et al. [23] Niger, Lankoandé et al. [16] Burkina Faso (1995) and Traore et al. [19] in Mali (2008) reported that $62.5 \%$ respectively, $71.5 \%, 81 \%$ of deaths occurring within less than 24 hours after admission. This is explained by the already moribund state in which women were coming.

\section{Conclusions}

Maternal mortality remains a public health problem in the Democratic Republic of Congo in general and in the province of Haut Katanga in particular.

Haemorrhage, eclampsia and infections are the main causes of maternal deaths in the reference provincial hospital Jason Sendwe. The majority of these deaths occurred within 24 hours of admission. It is then possible to make the bleeding a minor cause of maternal mortality in hospitals in Black Africa in strengthening its fight by facilitating access to emergency medication, transfusion and surgical and anesthetic teams in middle hospital.

Reducing the maternal mortality rate is not only through political decisions but also through the involvement of religious and traditional authorities or community to better understand the population obstacles to reducing maternal mortality. It means strengthening awareness on prenatal care, screening for high-risk pregnancy, family planning and assignment of qualified staff in general hospitals reference may contribute to the improvement of maternal health. Medical transport means as well as a hotline would also have an impact on the effective management of emergencies. It is also vital to strengthen the fight against obstetric haemorrhage by facilitating access to Emergency drugs, transfusion and Surgical and anesthetic surgeries in hospitals.

\section{References}

[1] ADB, WHO, AU, UNDP (2011) Assessing Progress in Africa toward the Millennium Development Goals. MDG Report, 53. 
[2] World Health Organization (1977) International Classification of Diseases, Revision 1975. World Health Organization, Geneva.

[3] Philibert, M.F. and Boibras Bouvier-Colle, M.H. (2003) Epidemiology of Maternal Mortality in France from 1996 to 2002: Frequency, Causes and Factors. Inserm (1) 149, University Pierre et Marie Curie, Paris.

[4] CEMACH (2004) Confidential. Enquiry into Maternal Deaths Why Die Matters 2000-2002. London, 25-58.

[5] Wildman, K. and Bouvier-Colle, M.H. (2004) Maternal Mortality as an Indicator of Obstetric Care in Europe. British Journal of Obstetrics and Gynaecology, 111, 164169. https://doi.org/10.1046/j.1471-0528.2003.00034.x-i1

[6] Deneux-Tharaux, C., Berg, C., Bouvier-Colle, M.H., Gissler, M., Harper, M. and Nannini, A. (2005) Underreporting of Pregnancy-Related Mortality in the United States of America and Europe. Obstetrics \& Gynecology, 10, 684-692. https://doi.org/10.1097/01.AOG.0000174580.24281.e6

[7] Ronsmans, C. and Graham, W.J. (2006) Maternal Mortality: Who, When, Where, and Why. Lancet Maternal Survival Series Steering Group, Graham.

[8] WHO and UNICEF (2007) Maternal Mortality in 2005. Estimates Developed by WHO, UNICEF, UNFPA and the World Bank, Geneva.

[9] National Programme for Family Planning DRC Facts DRC Country Sheet, 2012.

[10] World Health Organization (2005) Health Report in the World. Opportunities for Every Mother and Every Child. WHO, Geneva. http://apps.who.int/entity/whr/2005/02_contents_fr.pdf

[11] Tebeu, P.M. Ngassa. P., Kouam, L., Major, G. and Fomulu, J.N. (2007) Maternal Mortality in Maroua Provincial Hospital, Cameroon (2003-2005). West Indian Medical Journal, 56, 502-507.

[12] Kilolo Ngoy Umba Elijah Bwana Kangulu. I., Ngoy Lumbule, J., Kabamba Nzaji, M. and Mwembo Tambwe, A.N. (2015) Maternal Mortality in the Rural Health Zone of Butumba (DR Congo). Annals of the University of Kamina, 14.

[13] Kodio, B., Bernis, L., Ba, M., Ronsmans, C., Pison, G. and Ltard, J.F. (2002) Levels and Causes of Maternal Mortality in Senegal. Tropical Medicine \& International Health, 7, 499-505. https://doi.org/10.1046/j.1365-3156.2002.00892.x

[14] Prual, A., Bouvier-Colle, M.H., de Bernis and Breart, G. (2000) Severe Maternal Morbidity from Obstetric Causes Live in West Africa: Incidence and Case Fatality Rates. Bulletin of the World Health Organization, 78, 593-602.

[15] Supratikto, G., Wirth, M.E., Achadi, E., Cohen and Ronsmans, C. (2001) A District-Based Audit into the Causes and Circumstances of Death Maternal in South Kalimantan, Indonesia. Bulletin of the World Health Organization, 80, 228-234.

[16] Lankoandé, J., Ouédrogo, C.H., Touré, B., Ouédraogo, A. and Kone, B. (1998) Maternal Mortality Maternity Hospital Centre National de Ouagadougou (Burkina Faso). About 123 Cases Diagnosed in 1995. Black African Medicine, 45, 187-190.

[17] Horo, A. (2008) Toure. Médecine d Afrique noire, 55, 450-453.

[18] Gandzien, P.C. (2005) Maternal Mortality in Hospital of Brazzaville Talangai. Médecine d' Afrique noire, 52, 657-660.

[19] Traoré, B., Thera, T.A., Kokaina, C., Beye, S.A., Mounkor, N., Téguété, I. and Dolo, A. (2008) Maternal Mortality in Obstetrics and Gynecology Department of the Regional Hospital Segou in Mali Retrospective Study of 138 Cases. Le Mali Medical, 25, 42-47.

[20] Maguirada, M.R. (2000) Study of Mortality in Mali. Cause and Risk Factors to the 
Reference Health Center in the Town of V Bamako District. Thesis, Med., Bamako.

[21] WHO Joint WHO/UNFPA/UNICEF/World Bank (1999) Reducing Maternal Mortality. 618.2. WHO, Geneva.

[22] Foumane, P., Dohbit, J.S., Ngo, U., Meka, E., Nkada, M.N., Ze, M.J. and Mboudou (2015) Etiologies of Maternal Mortality in Obstetrics and Gynecology Hospital and Pediatric Yaounde: A 58 Death Series. Health and Science, 16. www.hsd-fmsb.org

[23] Nayama, M., Djibo, A. and Garba, M.R. (2006) Maternal Mortality at a Reference Maternity of Niger: Prospective Study about 104 Cases. Médecine d Afrique noire, 53, 687-693.

Submit or recommend next manuscript to OALib Journal and we will provide best service for you:

- Publication frequency: Monthly

- 9 subject areas of science, technology and medicine

- Fair and rigorous peer-review system

- Fast publication process

- Article promotion in various social networking sites (LinkedIn, Facebook, Twitter, etc.)

- Maximum dissemination of your research work

Submit Your Paper Online: Click Here to Submit

Or Contact service@oalib.com 